\title{
PROMOTING MODELING AND COVARIATIONAL REASONING AMONG SECONDARY SCHOOL STUDENTS IN THE CONTEXT OF BIG DATA
}

\author{
EINAT GIL \\ University of Toronto and Levinsky College of Education \\ einat.gil@levinsky.ac.il \\ ALISON L. GIBBS \\ University of Toronto \\ alison.gibbs@utoronto.ca
}

\begin{abstract}
In this study, we follow students' modeling and covariational reasoning in the context of learning about big data. A three-week unit was designed to allow $12^{\text {th }}$ grade students in a mathematics course to explore big and mid-size data using concepts such as trend and scatter to describe the relationships between variables in multivariate settings. Students' emergent ideas were followed along a varied learning trajectory that included computer-supported collaborative and inquiry-based approaches, using visualization tools and statistical software to explore data and fit a suitable trend, and student presentations of investigations. Findings show progress in some components of students' reasoning and modeling of covariation, and indicate which features of the unit design might contribute to it.
\end{abstract}

Keywords: Statistics education research; Statistical modeling; Design of learning environment; Representational gestures

\section{INTRODUCTION}

Current trends in statistics include a growing awareness of the need for data-driven decision-making and increasing attention to the availability of big data and its potential to significantly alter data-based decision-making processes (Agrawal et al., 2012). Yet current opportunities to experience big data in statistics education are limited in tertiary education and are even more so at the secondary school level. Coupled with the growing attention to big data, there is a growing recognition of the need for students to develop basic literacy with such data, and the need to develop frameworks to guide their learning, as illustrated by the pioneering attempt of Philip and colleagues to design activities using data that have some of the characteristics of big data at the secondary school level with mobile learning (Philip, Schuler-Brown \& Way, 2013).

Goals of the analysis of big data include exploring hidden structures in the data and understanding features that are common across subgroups (Fan, Han \& Liu, 2014). As a consequence, facility in covariational reasoning, both bivariate and multivariate, is essential in making sense of mid-size and big data. Modeling for exploring the association between variables, as described by Lehrer and Schauble (2010), is an essential tool to understand, discover, and describe covariational phenomena.

In this study, we examine a unit that was designed to promote secondary school

Statistics Education Research Journal, 16(2), 163-190, http://iase-web.org/Publications.php?p=SERJ

(C) International Association for Statistical Education (IASE/ISI), November, 2017 
students' covariational reasoning and modeling of and for covariational reasoning. Students worked in multivariate settings using big data or data with some characteristics of big data such as greater size, originating from different sources, and multivariate. The goal was to develop students' ability to make sound conclusions from the data.

\section{THEORETICAL FRAMEWORK}

This study followed students' covariational reasoning and their modeling of it while they investigated mid-size and big data through multivariate data explorations. Learning from previous studies and learning trajectories (e.g. Cobb, McClain, \& Gravemeijer, 2003; Engel, Sedlmeier \& Woern, 2008; Zieffler \& Garfield, 2009) our aim was to allow for emergent modeling of covariational reasoning in an inter-disciplinary, inquiry-based and technology-supported learning environment for $12^{\text {th }}$ grade students in a class unit designed for learning about big data. This section describes a few interconnected domains underlying the study: models and modeling in statistics and statistics education, covariational reasoning, learning about big data and, lastly, embodiment of students' reasoning through gestures that will serve as an introduction to one of the analytic methods.

\subsection{MODELS AND MODELING}

Modeling is used and described across different disciplines, including engineering, science, mathematics, and business. We limit ourselves to discussing it mainly in the statistical context, thus not considering a "model" in the sense of an example (such as its use in social science) or prototype (as in engineering and industrial design).

We use an adaptation of Lesh and Doer's definition that "models are conceptual systems, $[\ldots]$ that are used to construct, describe, or explain the behaviours of other systems" (Lesh \& Doer, 2003, p. 10). With models, there is an attempt to construct, describe or explain the "natural world" (Lehrer \& Schauble, 2010). Models can explain a scientific phenomenon or summarize patterns in data in what Lehrer and Romberg (1996) termed "a second-order modeling."

Lehrer and Schauble (2010) contended that a model is a form of explanation. The root of scientific explanation relates to understanding "why" (Nagel, 1979) and some also recognize the value of explanation to describe phenomena (Kuhn Berland \& Reiser, 2009). In the context of statistics education, where explanatory aspects of models can be used to help in understanding the "why" and "how" of informal inferential arguments (Gil \& BenZvi, 2011), models are also used to describe phenomena observed in data, capturing relations and structures in graphical, textual or mathematical form.

Modeling has long been recognized to play a vital role in statistical reasoning (Wild \& Pfannkuch, 1999) through the incorporation of uncertainty into an overall description of the data or of a phenomenon (Garfield \& Ben-Zvi, 2008). While a graph is considered by some to be a type of a model (Garfield \& Ben-Zvi, 2008; Wild \& Pfannkuch, 1999), for others the purpose of a graph is to describe the data as a step in the creation of a suitable statistical-mathematical model (Moore, 1999).

In statistical practice, models are generally recognized as serving one of two purposes (e.g. Shmueli, 2010). The first is known as generative, explanatory or descriptive. A generative model gives a mathematical representation of the process that resulted in the data, describing an underlying truth. Typical applications of a generative model are to evaluate whether one variable is associated with another, or to estimate the uncertainty associated with observations. The second purpose of models is predictive with the goal of 
predicting future observations, or predicting what might be observed as a result of an intervention.

In this study, we conceive of modeling as fitting a model to already existing data in order to describe and/or explain association in the data (Garfield \& Ben-Zvi, 2008). As such, our approach to modeling follows Lehrer and Schauble's (2004) recommendation that "the starting place for education should be with the world and the problems it presents, rather than with the models themselves" (p. 636). More of this approach is described in the section on covariational reasoning.

\subsection{COVARIATIONAL REASONING}

Covariational reasoning, or reasoning about association between variables, is also known as bivariate reasoning when it discusses a relation between two variables. It plays an important role in scientific thinking and has applications in several disciplines including mathematics, statistics, and social sciences (Garfield \& Ben-Zvi, 2008). The features attributed to learning bivariate reasoning are: exploring the variability of individual variables, attending to the shape and strength of the relationship, and generalising and explaining the relationship (Watkins, Scheaffer, \& Cobb, 2004). Models for covariational reasoning are generative since the purpose is typically to describe relationships and infer an underlying truth for how and why the data are what they are.

Reasoning about covariation is known to be challenging in the bivariate context for students in various age groups. Difficulties include focusing only on isolated bivariate points and handling a negative covariation that was counter to a prior belief of a positive association (Moritz, 2004, primary and middle school). Other known "traps" have been shown to exist, such as unidirectional (Batanero, Estepa \& Godino, 1997, college; Moritz, 2004) and causal misconceptions (Batanero et al., 1997).

Gravemeijer (2000) examined $8^{\text {th }}$ grade students' perceptions of local and global variation of bivariate data. A local view of a relationship considers various individual points in the data, while a global view also considers the characteristics of the general trend (Bakker \& Gravemeijer, 2004; Ben-Zvi \& Arcavi, 2001) in the bivariate data. Gravemeijer (2000) found that students were challenged to distinguish between arbitrary and structural covariation. His suggestion was that students should be allowed to investigate and compare some univariate datasets as preparation for bivariate data investigation. This suggestion was challenged by Zieffler and Garfield (2009) at the college level, who see the univariate and bivariate explorations as inseparably connected. A recent study on student conceptions of the line of best fit among $8^{\text {th }}$ grade students found that students had different conceptions of what a line of best fit is and hence they applied varying criteria to determine how to place it on a scatterplot (Casey, 2015).

In school curricula for mathematics and statistics, linear relations in the context of mathematical functions are typically addressed at the $8^{\text {th }}$ to $9^{\text {th }}$ grade level, and non-linear (quadratic and exponential) functions are addressed later in secondary school (e.g., Ontario (http://www.edu.gov.on.ca/eng/curriculum/secondary/math910curr.pdf), New Zealand (http://nzcurriculum.tki.org.nz/The-New-Zealand-Curriculum/Mathematics-and-statistics ), and U.S. (http://www.corestandards.org/Math/) curricula. The statistics strand of mathematics classes might include linear models for data (including the line of best fit) in the $9^{\text {th }}$ grade and the use of the correlation coefficient in $11^{\text {th }}$ or $12^{\text {th }}$ grade (e.g., Ontario (http://www.edu.gov.on.ca/eng/curriculum/secondary/math1112currb.pdf), New Zealand, U.S. curricula). In general, it is rare for students to fit non-linear models to data in the statistics context in secondary school. This emphasis on linear modeling in the curriculum might be a contributing factor to students' observed tendency to fit a linear model to data 
where a non-linear relationship exists or to data where there is no association (Casey, 2015; Moritz, 2004).

Using dynamic statistical technology tools (e.g., Fathom, iNZight) has been shown to be beneficial to the promotion of students' reasoning (Rubin \& Hammerman, 2006). These tools can relieve students from the burden of complex calculations such as the calculation of correlation coefficients, and allow students to fit models that are not linear, thus allowing students to extend modeling to include a variety of features observed in the data.

In this study's short unit, our aim was to explore a new conceptual and pedagogical approach in which students investigate multivariate data with various types of relationships, both linear and non-linear. In looking for a suitable statistical tool we chose iNZight (University of Auckland, Department of Statistics, 2014-17), a statistical visual tool that was developed for secondary school students and was found to enhance conceptual thinking to some extent (Forbes, Chapman, Harraway, Stirling, \& Wild, 2014). iNZight was chosen because it allows choices of different models for bivariate data, including local smoothers, and because it allows the investigation of the effect of a third variable through color-coding and through plotting subsets of the data conditional on the values of the third variable. This approach was inspired by the "From Data to Insight" MOOC (Wild \& Meek, 2014).

Our aim in this study was to investigate students' change in covariational reasoning over the course of the unit and the role that models played in their reasoning from an epistemological view. We developed a concept map (Figure 1) that builds both on our literature review and ongoing dialogue between the two authors (a statistics professor (AG) and a statistics education designer and researcher (EG)). Concept maps are commonly used as a tool for organising students' knowledge. Our use of concept maps served as an epistemological tool to map the main ingredients of evolving reasoning about a concept. The mapping started from the literature review and contributed to the design process, later on serving as a platform for the analysis of the research data. This in turn allowed further insight into the concept map in an iterative way (Gil, 2014).

The concept map was built upon the following sources:

1. Dimension of the association built upon big data literature (e.g. Franke et al., 2016) and studies that emphasise multivariate approaches to data (e.g. Ridgway, 2015).

2. Modeling of association ingredients built upon concepts used in the "From Data to Insight" MOOC and Wild and Seber (2000).

3. Views of the association built upon local and global views of the distribution (BenZvi \& Arcavi, 2001).

4. Representing the model related to the three different forms of representation of a model that emerged from our research data (textual, visual, and mathematical; Moritz, 2004).

5. Concluding from the association built upon the concluding stage of the investigative cycle (Wild \& Pfannkuch, 1999) together with modeling literature in statistics focusing on the aim of models - to predict or explain (e.g. Shmueli, 2010).

The concept map relates predominantly to two stages in the PPDAC cycle (Wild \& Pfannkuch, 1999) -- Analysis (dimension, modeling, views and representing) and Conclusion (Concluding). It serves as an evolving theoretical framework that guided our design of our study and the analysis of the data. 


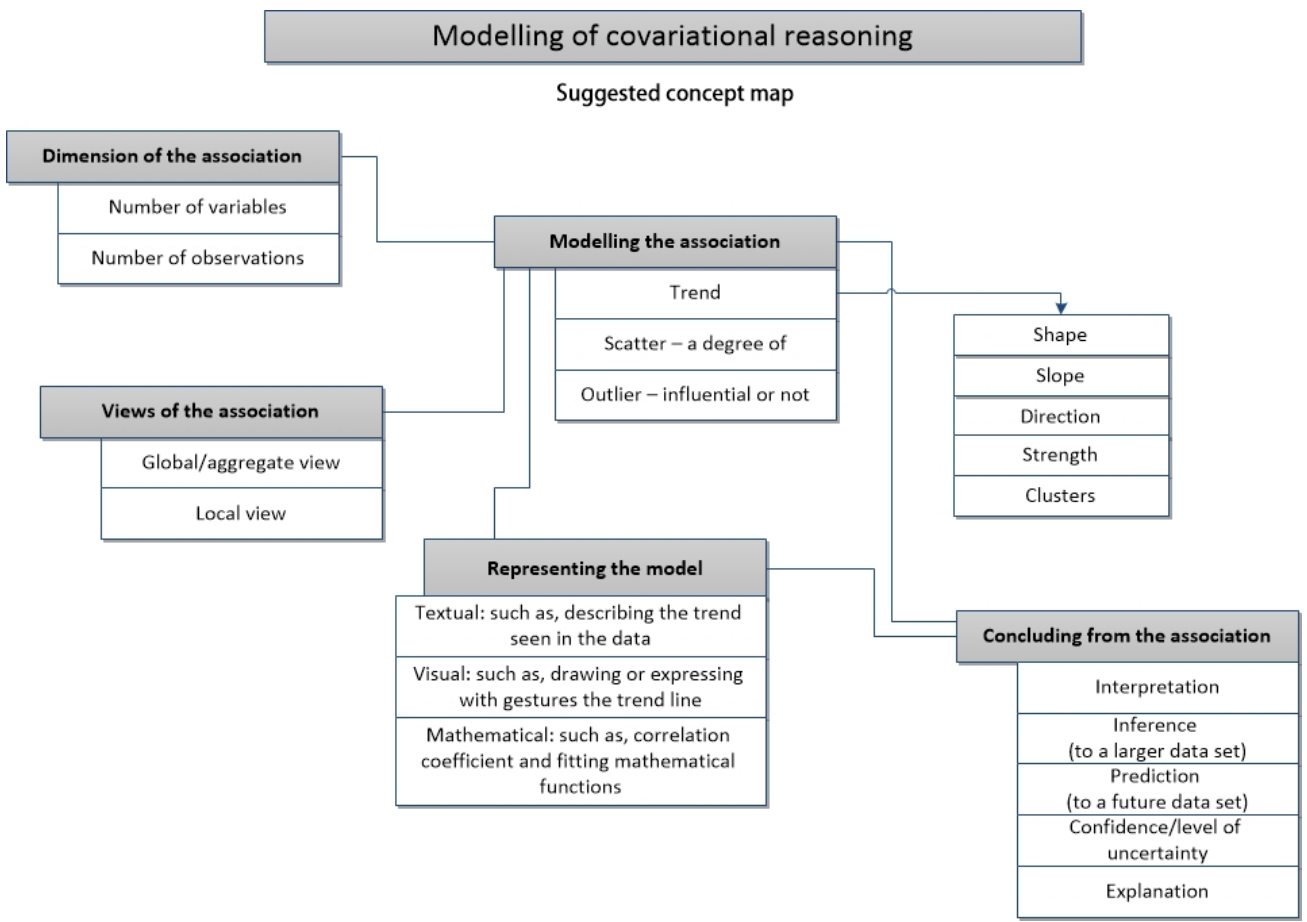

Figure 1. Modeling of covariational reasoning

\subsection{THE CONTEXT OF LEARNING ABOUT BIG DATA}

Big data has recently received much attention in industry and post-secondary research and education. It is commonly characterized by the four Vs - volume, velocity, variety and veracity (Beyer \& Laney, 2012) and some add an additional V, value (e.g., Thirunarayan, $\&$ Sheth, 2013). Numerous challenges in extracting useful information from big data are encapsulated in those Vs. Strategies to tackle them typically include "identifying and exploiting a hidden structure within the data" (Franke et. al, 2016).

Identifying hidden structure and investigating whether or not structures persist across subgroups (Fan et al., 2014) require facility in covariational reasoning. Thus, covariational reasoning and the use of modeling to explore associations between variables are necessary to develop deeper understanding of data in general (Lehrer \& Schauble, 2010) and big data in particular.

Ridgway (2015) addressed the need to modernize curricula in the context of open and big data and recommended that statistics education curricula: devote time to investigating open data using currently available examples, introduce multivariate data early, teach about and with interactive graphics, work with multiple data sources, include engagement with modeling (not only linear), and put more emphasis on decision making and risk. Concerning modeling, he suggested that "students should model the same phenomena in different ways and different phenomena using the same formalism"; and that, "critique of different models should be encouraged, as part of a process of developing an aesthetic of modeling" (p. 16).

Creating "citizen statisticians" who have experience analyzing available and complex data was suggested by Gould (2010) as a recommended aim to statistics education. This was illustrated through the Mobilize project which used streaming mobile data in a school 
setting in the context of democratic participation (Philip et al., 2013). The project demonstrated that working with big data at the secondary school level requires adequate simplification in concepts and processing tools and appropriate scaffolds for both technological and contextual platforms.

In this study, consideration was given to how the design of a learning environment could contribute to the development of secondary school students' understanding of big data and scaffold the development of skills needed to create meaning from complex data.

\subsection{GESTURES TO EMBODY REASONING}

In this study, we consider various ways to represent models, including textual, numerical, and visual/graphical expressions. In textual expression, students might express their ideas either in writing or verbally. Numerical description can take the form of a correlation coefficient or an equation of a mathematical function.

Students' graphical representations can be expressed either by drawing a trend line or depiction through gestural expressions. While textual, graphical and numerical representations are well known methods to describe or model phenomena in statistics, gestural expression as a way to describe a concept is less familiar in the literature and is described here.

Students' discourse provides a window to their thinking and learning (Sfard, 2007). Articulating reasoning processes is possible only to some extent through verbal means (Reiner \& Gilbert, 2004). Another way of articulation that serves as a window to students' perception and meaning making is to use gestures to depict mental imagery while describing or explaining phenomena during a learning activity. There is a wide array of studies exploring the place of gestures in human interaction, including education. Many of these studies build upon McNeill's (1992) typology of four main categories of gestures. Two of them - iconic gestures (portraying semantic content directly using the shape or motion trail of the hand), and metaphoric gestures (portraying semantic content using metaphor) are of particular relevance to our study. Those two were united into representational gestures, which portray aspects of their meaning, literally or metaphorically, and have been found to express mental recreations of action and perceptions via motion or shape of the hand (Alibali \& Nathan, 2012).

Alibali and Nathan (2012) looked at embodiment in learning and teaching mathematics and discovered that the use of representational gestures implies that explanation of mathematical thinking includes simulations of actions and visual images of mathematical objects/ideas, and simulations of the real-world situations of the problem context. They also added that students "may intentionally produce such gestures in order to facilitate thinking" about mathematical ideas or use them "to promote effective communication about such ideas" (p. 23). Representational gestures were also used in studies in physics education looking at the place of gestures in students' thinking as compared with experts' thinking in depicting mental imagery for object, force or event (Stephens \& Clement, 2010).

In this exploratory study, representational gestures provided additional insight into students' reasoning about covariation and modeling along with their textual, numerical, and graphical expressions. When students are faced with complex multivariate data, they might need to utilize more than their verbal knowledge to facilitate their thinking about, and expression of, structure and relations in the data. We identify gestures through the similarity to the shape of the model described by the student and/or as interpreted to be connected to the main modeling concepts. We did not aim to create a more complex categorization for gestures in statistical reasoning. Thus, for example, a diagonal linear 
gesture in conjunction with speaking about the appropriate model was identified as representation of the linear model.

\section{METHOD}

We employ a design-based approach (Barab \& Squire, 2004; Brown, 1992) that aims at developing and implementing a new curriculum as well as generating assertions supported by evidence about learning that relates and adds to current theoretical issues (Barab \& Squire, 2004). It adheres to the five characteristics of design research (Cobb, Confrey, diSessa, Lehrer \& Schauble, 2003; Prediger, Gravemeijer, \& Confrey, 2015) as providing a program that is interventionist, striving to contribute to theory, reflective upon the process of learning and design, including more than one iteration, and ecologically valid.

In a program that aims at promoting covariational reasoning and the application of modeling for covariational reasoning in the context of big data we ask:

1. What are the characteristics of students' covariational reasoning and modeling in the context of big and multivariate data, and how did it change during the program?

2. What design features promoted their emergent covariational reasoning and modeling?

\subsection{PARTICIPANTS}

The study took place in a natural school setting with two 12th grade classes (age 17$18 ; \mathrm{n}_{1}=25, \mathrm{n}_{2}=30$ ) at an Ontario secondary school in which most of the students were above average academic level. Results are given from the focal class $\left(\mathrm{n}_{1}\right)$, which usually had the second iteration of the activities between the two classes.

In our analysis, we focused primarily on six groups of students but attended also to discussions with additional students in class. The students in these groups were articulate, like many of the other students in both classes, and were chosen to provide a valuable source of information about their learning and reasoning processes as they presented their investigations (intensive sampling method, Patton, 2002). Table 1 describes the observed students and how they were selected.

The students were enrolled in a $12^{\text {th }}$ grade class, Mathematics for Data Management (MDM4U), one of the three elective university preparatory mathematics courses (Ontario Ministry of Education, 2007). The students did not have much experience with statistics. They had not encountered data in their mathematics class since the unit on the mathematics of the straight line in 9th grade (Ontario Ministry of Education, 2005). During the $9^{\text {th }}$ grade they discussed relationships between dependent and independent variables and modeling terminology including trend and line of best fit. The students were somewhat familiar with Gapminder (http://www.gapminder.org/world/ ) from a social science course, but had not used statistical software other than Microsoft Excel ${ }^{\mathrm{TM}}$. In MDM4U, a substantial part of the course curriculum is topics in probability (two out of five units). Prior to the study unit, the mathematics teacher for the study classes taught the probability units and approached the course from a mathematical perspective.

\subsection{THE RESEARCH SETTING}

The study involved the design and implementation of a learning environment for a statistics unit that constituted five activities over six 72-minute sessions for each class. Different aspects of the design were presented to all collaborators, including the teacher, who decided to take a supportive side role, relinquishing his role as the primary teacher for the unit. 
Thus, the teaching and research documentation were carried out by the two authors in a compact and intense three weeks.

Table 1. Participants in the study

\begin{tabular}{|c|c|}
\hline Section & Participants and sampling method \\
\hline $\begin{array}{l}\text { 4.1. Students' initial covariational } \\
\text { reasoning }\end{array}$ & $\begin{array}{l}3 \text { groups, volunteered: } \\
\text { Group 1: Galya, Sharon } \\
\text { Group 2: Cathy, Andrei } \\
\text { Group 3: Chad, Annie } \\
\text { Participants in class discussion: Galya, Carly, Amilia }\end{array}$ \\
\hline 4.2. Further emergence of ideas & $\begin{array}{l}\text { One student (Ron) out of two volunteered for the } \\
\text { "recreating the scatterplot" exercise in the focal class. } \\
\text { The other one did not have video permission, thus } \\
\text { could not be analyzed in visual analysis }\end{array}$ \\
\hline $\begin{array}{l}\text { 4.3. Continuation and change in } \\
\text { perception of modeling for covariation }\end{array}$ & $\begin{array}{l}3 \text { groups chosen (out of } 6 \text { presenting) that had at least } \\
1 \text { student from the first activity presentation: } \\
\text { Group A: Sharon Amilia } \\
\text { Group B: Galya, Tessa and Karin } \\
\text { Group C: Annie, Nicole } \\
\text { (At times reference is made to all groups in both } \\
\text { classes) }\end{array}$ \\
\hline
\end{tabular}

The learning trajectory combined explorations of mid-size data using Gapminder and iNZight with an interdisciplinary collaborative activity for learning about big data that took place in an Interactive Orchestrated Learning Space (IOLS; Gil \& Slotta, 2015). The IOLS is a transformed classroom using a technology infrastructure to connect to big data resources, with a generic collaborative platform for communication and knowledge building (Gil \& Gibbs, 2016). The learning trajectory, highlighting statistical ideas of covariational reasoning and modeling, is shown in Table 2. Gapminder World (Gapminder for short) is a visualization tool to present data collated from almost all countries across different indexes. Its primary representation is a bubble chart, a variation of scatterplot that uses the bubble size to indicate quantity (e.g., country population size). It also uses color to indicate the values of categorical variables (such as region). It was used in the first activity since it allows easy access into visualizing correlation (e.g., Le, 2013). In the second activity students' learning was orchestrated through interdisciplinary stations demonstrating the use of big data in different contexts, such as social networks, health (Google Flu Trends and CDC data) and ecology (visual forest fire data). In each station the students interacted with the content, discussed and answered questions relating to the big data resource, and submitted their responses using Google forms embedded in the course website. Their answers were collected into a knowledge base (KB) to be used in the following activity (for more elaboration on activity 2, see Gil \& Gibbs, 2016). In the third activity, the students constructed community knowledge on big data based on the KB (Gil \& Gibbs, 2016; Gil \& Slotta, 2015), discussed seasonal trends in the Google flu model, and then participated in "Recreating the scatterplot from the trend exercise" (activity $3 a$ ). In the next class (activity 3b) they learned tools in iNZight to develop facility in investigating association in a multivariate context.

In the last two activities, the students explored the Wellbeing Toronto website and analyzed data exported from it using iNZight. For these final activities, students investigated a topic of their own choosing that included an examination of the 
Table 2. Learning trajectory

\begin{tabular}{|c|c|c|c|}
\hline Activity & $\begin{array}{l}\text { Class } \\
\text { Session }\end{array}$ & Content & Statistical ideas and concepts \\
\hline 1 & 1 & $\begin{array}{l}\text { Trends in the World of Data } \\
\text { Introduction to mid-size data } \\
\text { inquiry with Gapminder }\end{array}$ & $\begin{array}{l}\text { Data analysis and covariation in mid-size } \\
\text { data; Examining initial ideas of } \\
\text { covariational reasoning and modeling }\end{array}$ \\
\hline 2 & 2 & $\begin{array}{l}\text { Big data interactive } \\
\text { Experiencing and learning } \\
\text { about big data in an Interactive } \\
\text { Learning Environment (IOLS) }\end{array}$ & $\begin{array}{l}\text { Learning about different aspects and } \\
\text { application of big data from examples in } \\
\text { an inter-disciplinary context }\end{array}$ \\
\hline $3 a$ & 3 & $\begin{array}{l}\text { Discussion about aspects of big } \\
\text { data }\end{array}$ & $\begin{array}{l}\text { Reflecting on characteristics of / insights } \\
\text { about big data; Using models to predict } \\
\text { trends in the populations (Google Flu) }\end{array}$ \\
\hline & & $\begin{array}{l}\text { Recreating the scatterplot from } \\
\text { the trend exercise }\end{array}$ & $\begin{array}{l}\text { Emerging ideas about modeling of } \\
\text { covariation }\end{array}$ \\
\hline $3 b$ & 4 & $\begin{array}{l}\text { Introduction to iNZight and } \\
\text { covariational tools }\end{array}$ & $\begin{array}{l}\text { Investigating bi- and multivariate data; } \\
\text { Learning tools for modeling of covariation } \\
\text { with training data using iNZight }\end{array}$ \\
\hline 4 & $4 / 5$ & $\begin{array}{l}\text { Introduction to Wellbeing } \\
\text { Toronto site; Toronto } \\
\text { exploration with iNZight }\end{array}$ & $\begin{array}{l}\text { Investigating bi- and multivariate mid-size } \\
\text { data through spatial visualization and } \\
\text { exploring relationships between variables } \\
\text { using iNZight }\end{array}$ \\
\hline 5 & 6 & Students' big data pitch & $\begin{array}{l}\text { Presenting findings from investigation of } \\
\text { mid-size data; Examining the progress of } \\
\text { covariational reasoning and modeling }\end{array}$ \\
\hline
\end{tabular}

relationship between two or more variables, and presented their findings. The teaching was supported by a unit website (https://bigdatamdm.wordpress.com) with activities revealed one at a time before each class session. The focal class completed most activities one or two days later than the other class, and experienced a slightly improved design of the activities.

We now elaborate on the activities from which research data were analyzed in the results. In the first investigation (Activity 1), the students used one of three specific indicators in Gapminder (children per woman, income per capita, or how far to the north) and explored its relationship with one of several education indicators (e.g., literacy rate, school enrolment). They could also explore how the variables and their relationships changed over time (dynamic time series) and region of the world (indicated by color). The students interpreted and described the scatterplots and the trends observed and wrote briefly in a shared Google document. Three groups presented their findings to the class. This activity served in this study to show students' initial perceptions of modeling of covariation (see results in section 4.1).

The "Recreating the scatterplot from the trend" exercise (part of Activity 3a; Gil \& Gibbs, 2015) aimed to capture emerging ideas about modeling. In this exercise, a volunteer student was asked to leave the room for two minutes while the rest of the students were shown a scatterplot (e.g., Olympic 100 meter running results over time for men and women). They then had to instruct the volunteer student to recreate the scatterplot on the board, focusing on the trend, without revealing the context of the data. This activity assisted in describing further emergence of ideas (see section 4.2).

Additionally, students learned to use association and modeling tools in iNZight with test data through a written instructional activity. In the final exploration (Activities 4-5), the students used both spatial visual representations of data from the Wellbeing Toronto 
website (year 2011; e.g., Figure 2) and exported data to iNZight to explore and model the relationships between two or more variables. The Wellbeing Toronto data were collected on all of the neighborhoods of Toronto and include indicators of health, education, crime, ethnicity, etc. (http://map.toronto.on/wellbeing). The students chose topics of their own interest and posed questions in groups. They explored the data and various models to describe the trend (see an example in Figure 3) and deviations from it and gave plausible explanations for their findings. Through this activity, the students investigated authentic data about their city and prepared data-supported arguments to pitch suggestions for improvements to the newly elected mayor. Presentations from this activity served to show students' continuation and change in perception (section 4.3). Teachers actively intervened to encourage the emergence of the main concepts and ideas, prompting the students when those did not rise voluntarily.

\subsection{DATA AND ANALYTIC METHODS}

All activities and discussions in the two classes were videotaped while respecting restrictions on video permission for some students. During the first and fifth activities, there were two video cameras located in the classroom aimed to capture student presentations and interactions between the presenting students and other students and class discussion. Not all interactions were captured and although video data is considered to be a comprehensive capturer of research data, the decisions about what and how to capture are somewhat influenced by the research questions (The $\mu$ Group, 2001). Additionally, a pretest and posttest were administered. Quantitative analysis was carried out on a sample from the responses to the pretest and posttest but this is not reported here due to relatively low quality in student effort and rate of completion in the covariational reasoning part of the posttest. We report here only on the qualitative analysis of data from the videos.

Students' presentations and selected discussions were transcribed and analyzed using content analysis, capturing the main ideas connected to the theoretical framework that emerged from the research data (Chi, 1997). For this purpose, we looked more carefully at the presentations of data investigations carried out by six groups. From those groups, the work of three students was captured for both activities. The presentations and discussions were coded for evidence of covariational reasoning and aspects of modeling for covariational reasoning, such as strength or direction of the trend, as manifested in the suggested concept map (Figure 1). We then coded expressions in the transcript that represented the aspects in the map and summed those in a comparative way between the groups. To achieve more accuracy, we conducted triangulation of coding between the first and second authors and discussed disputed cases until agreement was achieved.

When coding verbal ideas relating to the components of covariational reasoning and modeling, we differentiated between literal (L) and explained (E). A student made an L reference when he or she mentioned a concept relating to the covariation and modeling, using the vocabulary in the suggested concept map (Figure 1). Some examples of L references are "we see a trend in the graph," "the strength of the relation is high," "there is a bit of scatter in the left." An E reference occurred when students explained a concept but didn't mention it literally, such as in relation to direction: "as the fertility rate goes up, so does poverty rate." We differentiate between the two in order to identify both aspects relating to students' perception of concepts. While spoken language reflects thinking (Sfard, 2007), language of an expert will include more concepts, demonstrating knowledge of the content area (e.g. Meskill, Mossop, DiAngelo, \& Pasquale, 2002). A student might remember the technical word for a concept, but present only partial 


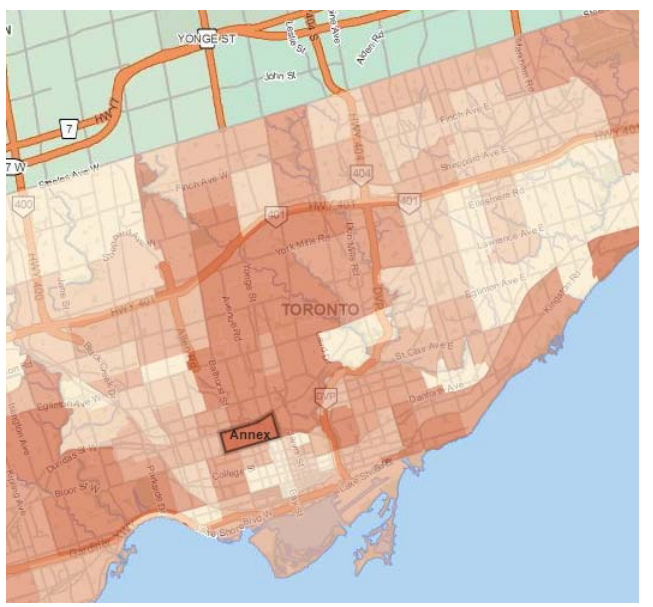

Figure 2. House prices in Toronto neighborhoods, darker colors represent higher house prices (Wellbeing Toronto website)

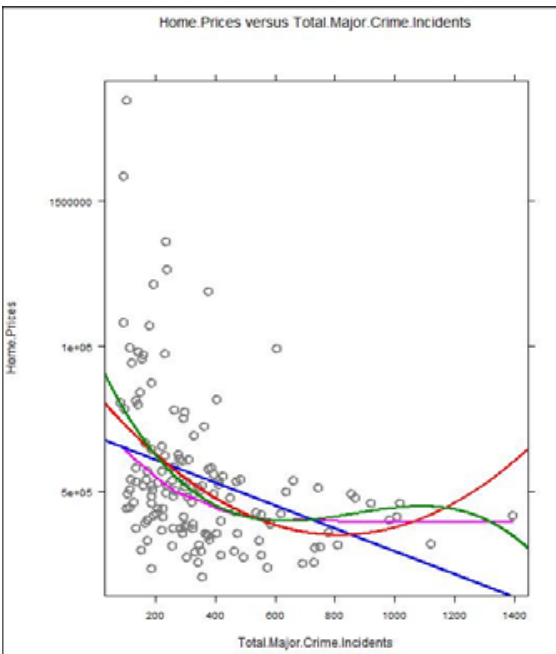

Figure 3. Fitting trend curves to data in iNZight (2011 data exported from

Wellbeing Toronto; each dot represents a neighborhood)

understanding while at other times a student might explain the concept well, but not remember the name of it. Identifying these two aspects can provide richer insight into students' reasoning (Gil, 2014).

In some instances, we used interpretive microanalysis (e.g. Meira, 1998), a detailed analysis that relates to students' verbal, gestural and symbolic actions within the activity in which they occurred. The analysis aimed to closely follow students' work while looking at the activity as a whole and analysing typical examples. We traced how students' perceptions changed through the learning process in a socio-constructivist learning environment. To this end, conceptual components of covariational reasoning and modeling were identified in students' expressions by two experienced researchers, discussed, and interpreted in relation to students' perceptions. Those interpretations were done while taking into account evidence supporting alternative interpretations. In addition to textual expression, we looked at the gestures students made when speaking, while they were describing and explaining their thinking. In the context of this study, these representational gestures (Alibali \& Nathan, 2012) added to the students' portrayal of the perceived relationships between variables and modeling of these relationships, including indications of direction, slope and shape of the trend line.

In the "Recreating the scatterplot from the trend" exercise, we used an adaptation of interpretive microanalysis applied to visual data to create a visual story of ideas. In this case, the visual activity in the video was screenshot approximately every two seconds to create a visual transcript which was coupled with the textual transcript. Then, key stages were identified and labelled in relation to the students' use of modeling to describe covariation. Being attentive to both textual and visual aspects of student activity enhanced our ability to follow and document students' reasoning.

\section{RESULTS}

Findings regarding the first research question on the characteristics of students' covariational reasoning and modeling in the context of big and multivariate data and how 
they change during the program are presented in Sections 4.1 to 4.3. Findings regarding the second research question on what design features promoted students' emergent covariational reasoning are presented in Section 4.4.

\subsection{STUDENTS' INITIAL COVARIATIONAL REASONING AND MODELING}

Activity 1, in which students explored world indicators using Gapminder graphical tools, exposed the initial state of students' covariational reasoning and modeling. In this section, we describe the analysis of three groups' presentations from their investigations in Gapminder, and a follow-up class discussion of a researcher initiated Gapminder plot of a non-linear relationship.

Covariational Reasoning and modeling in students' first presentations Three groups in the focal class presented findings from their Activity 1 investigation using Gapminder tools. Table 3 gives the opening statement for each of these groups. The variety of ways that students demonstrated covariational reasoning and the ways they used modeling concepts for covariational reasoning were extracted from these statements and the subsequent presentations' statements and class discussions, which included ideas that arose after prompting by the teacher-researchers.

Table 4 gives a summary of the characteristics of covariational reasoning that students demonstrated in their presentations of the first activity. Two of the three groups expressed covariational reasoning, describing how the behavior of one variable tended to vary with the value of at least one other variable. Within group 1 this was not consistent - they moved between bivariate and multivariate reasoning. In group 3, Annie and Chad ignored income per person, although it was plotted on the horizontal axis of the plot, and most of the observations on their plot. Instead they observed the behavior of children per women in only one country (the US) over a few years, which can be described as local bivariate reasoning (time being the second variable). Group 3 demonstrated no modeling of association. Group 2 was the only group explicitly mentioning "Trend" (L \& E) and describing the trend they observed, but the use of the word occurred only after it was mentioned by the researcher in a summary of the discussion following Group 1's presentation. Although they did not use the word, Group 1 referred to some aspects of the trend in their presentation. Group 2 presented by far a more sophisticated use of modeling language, referring to more characteristics of the trend. Andrei spoke about the shape as a "linear relation" and about the strength - "a really strong trend." His interpretation of strength, however, was not related to how closely the points were scattered about the trend line, instead initially elaborating that the strength was reflected in the fact that the relationship was "very stable through the years." Later in the presentation, he related the amount of scatter to the strength of the relationship. Group 1 related to strength after prompting; they observed that "in a given year it is a pretty good predictor, but there is still a lot of variation."

Both Groups 1 and 2 related literally to clusters in the data. Group 1 mentioned "clusters" (L) without prompting but with only partial understanding of how this was relevant to modeling the association. In Group 2, Andrei explained the presence of clusters (E), referring to points representing African versus European countries. None of the three groups referred to slope. Group 2 described the direction of the trend (E), but did not literally state the direction (e.g., positive/negative). The use of literal terms for direction and a non-linear shape of the trend only emerged after two direct prompts from the researcher, who asked about the difference in the relationships that could be seen in two graphs illustrating relationships between different variables. Scatter was referred 
Table 3. Student opening statements for Activity 1, illustrating their initial modeling of covariation

\begin{tabular}{|c|c|c|}
\hline Group & Graph and Questions & Opening statement \\
\hline $\begin{array}{l}\text { Group } 1 \\
\text { Galya, } \\
\text { Sharon }\end{array}$ & $\begin{array}{l}\text { How does wealth (GDP per } \\
\text { capita) affect the adult literacy } \\
\text { rate in the years 1975-2011? }\end{array}$ & $\begin{array}{l}\text { We compared literacy rate adult total } \\
\text { percentage people ages } 15 \text { and up and } \\
\text { Income per person, GDP per capita inflation } \\
\text { adjusted. So, as you can see here, there is a } \\
\text { relationship between GDP per capita and } \\
\text { literacy rate. There is a lot of cluster near the } \\
\text { top, but also it is not totally independent } \\
\text { (Sharon) }\end{array}$ \\
\hline $\begin{array}{l}\text { Group } 2 \\
\text { Cathy, } \\
\text { Andrei }\end{array}$ & 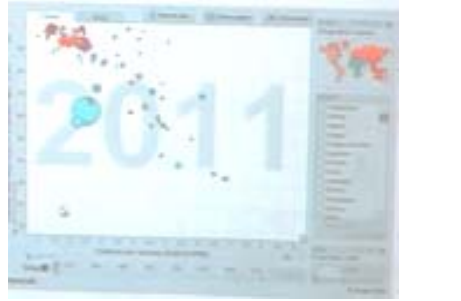 & $\begin{array}{l}\text { There is a pretty linear relationship between } \\
\text { fertility rate and literacy rate throughout the } \\
\text { years, and specifically the relationship that } \\
\text { high literacy rate is low fertility rate and vice } \\
\text { versa. [...] So, it seems to be a very strong } \\
\text { trend, because it is very stable throughout the } \\
\text { years, not very dependent on many other } \\
\text { things, as it appears (Andrei) }\end{array}$ \\
\hline & $\begin{array}{l}\text { What is the relationship between } \\
\text { literacy rate and fertility rate? }\end{array}$ & \\
\hline \multirow[t]{2}{*}{$\begin{array}{l}\text { Group } 3 \\
\text { Chad, } \\
\text { Annie }\end{array}$} & & \multirow{2}{*}{$\begin{array}{l}\text { We looked at children per woman vs income } \\
\text { per person.but we are looking at the great } \\
\text { depression and we found that the during the } \\
\text { great depression especially in the United } \\
\text { States the fertility rate decreased, and then, } \\
\text { after the great depression it kind of stayed low } \\
\text { because of the war, and then after the war it } \\
\text { increased. And then in the baby boom it } \\
\text { increased, and it is mostly in the United States } \\
\text { (Annie) }\end{array}$} \\
\hline & $\begin{array}{l}\text { Is there a correlation between the } \\
\text { Great Depression and Children } \\
\text { Per Woman? }\end{array}$ & \\
\hline
\end{tabular}

to by Group 2, who mentioned the "variation" in the data about the trend. And both Groups 1 and 2 spoke literally or explained cases that might be considered outliers.

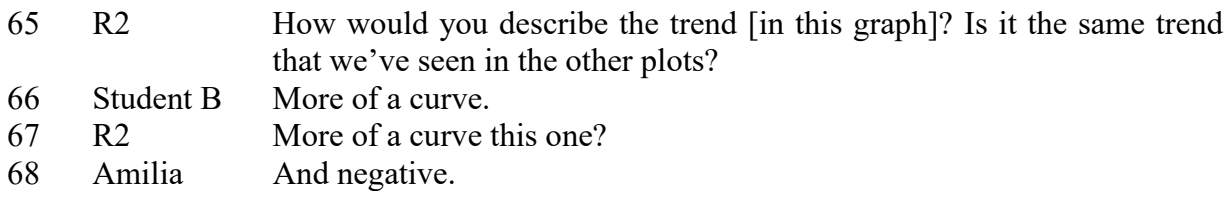

Class discussion of a non-linear relationship Owing to our design approach to promote covariational reasoning in the context of multivariate data and to promote variety in the models that were appropriate for the data, we introduced to the class a plot showing data with a clearly non-linear relationship. The northern latitude of a country (how far to the north) was plotted on the horizontal axis and mean years in school for women above age 25 was plotted on the vertical axis (see Figure 4 for a plot similar to this, showing mean years in school for women aged 25-34, reflecting a modification 
Table 4. Students' use of covariational reasoning and modeling in presentations of Activity 1

\begin{tabular}{llll}
\hline Characteristics & $\begin{array}{l}\text { Group 1 } \\
\text { Sharon, Galya }\end{array}$ & $\begin{array}{l}\text { Group 2 } \\
\text { Andrei, Cathy }\end{array}$ & $\begin{array}{l}\text { Group 3 } \\
\text { Annie, Chad }\end{array}$ \\
\hline $\begin{array}{l}\text { Covariational reasoning } \\
\text { Trend }\end{array}$ & $3 \mathrm{x}$ & $\begin{array}{l}3 \mathrm{x} \\
\mathrm{x}(\mathrm{L}, \mathrm{E})\end{array}$ \\
$\begin{array}{l}\text { Shape } \\
\text { Slope }\end{array}$ & & $\mathrm{x}(\mathrm{L})$ & \\
$\begin{array}{l}\text { Direction } \\
\text { Strength }\end{array}$ & & $\mathrm{x}(\mathrm{E})$ & \\
Clusters & $\mathrm{x}(\mathrm{E})$ & $\mathrm{x}(\mathrm{L}, \mathrm{E})$ & \\
Scatter & $\mathrm{x}(\mathrm{L})$ & $\mathrm{x}(\mathrm{L}, \mathrm{E})$ & \\
Outlier & $\mathrm{x}(\mathrm{E})$ & $\mathrm{x}(\mathrm{L})$ & \\
\hline
\end{tabular}

Mentioned: $2 \mathrm{x} / 3 \mathrm{x}=\#$ of times; $\mathrm{x}(\mathrm{E})=$ explicitly; $\mathrm{x}(\mathrm{L})=$ literally $\mathrm{x}(\mathrm{L}, \mathrm{E})=$ explicitly\& literally

to the variable in Gapminder). Table 5 is a transcript of the resulting class discussion, with meaningful hand gestures indicated by [ [ 3 ]

Analysis of this discussion reveals interesting use of gestures accompanying verbal expression by three different students. Galya was the first to describe the shape or the trend. Her hands showed both the V shape which she described verbally and an attempt to account for the width of the V, indicating the scatter around it (77). Carly moved her hand up and down twice while describing the scatter plot shape near the equator (78). This might suggest that when she said "drops," Carly also tried to account for the larger scatter in points from countries near the equator and not only a drop in the line, as she literally said. Finally, Amilia described the trend by explaining how it differed on either side of ("going to and from") the equator. When asked about the strength, she said that it was rather weak and when asked by the researcher what she meant by weak, she indicated a lack of confidence in her conception of strength (87). For Amilia, a trend was a line that is easy to "put your hand on." In a weak relation, it is difficult to distinguish the line from the noise, which she referred to as "outliers." Her perception, which may be intuitive or may be acquired from previous study, was that the clearer the line, the stronger the relation and she was able to apply this perception to a non-linear relationship, though her perception of strength was vague.

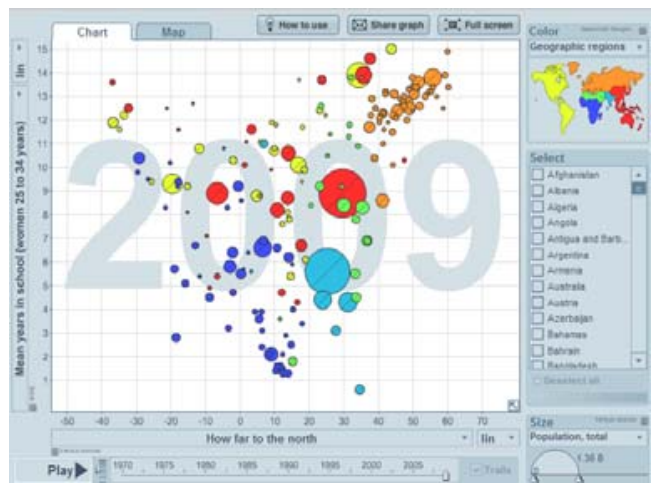

Figure 4. A graph showing a non-linear relationship: How far to the north and Mean years in school for women aged 25-34; this graph is similar to the graph shown in class, reflecting a modification in Gapminder to the variable on the vertical axis 
Table 5. Transcript of the class discussion on modeling non-linear distribution

\begin{tabular}{|c|c|c|c|}
\hline \# & Speaker & What was said & What was done \\
\hline 76 & $\mathrm{R} 1$ & $\begin{array}{l}\text { What can you make from this graph and } \\
\text { the trend of this graph? }\end{array}$ & $\begin{array}{l}\text { [Figure } 4] \\
\text { How far to the north and Mean } \\
\text { years in school, women above } 25\end{array}$ \\
\hline 77 & Galya & $\begin{array}{l}\text { It is kind of like }[\mathrm{m} /] \text { like a latch shape, } \mathrm{V} \\
\text { shape almost, where at the very north end } \\
\text { and the south end women spend average } \\
\text { more years in school, it appears. }\end{array}$ & \\
\hline 78 & Carly & $\begin{array}{l}\text { And then, closer to the equator, at least for } \\
\text { some places, that's Africa right, sub- } \\
\text { Saharan Africa. In those places, that's } \\
\text { where [ } \mathrm{m} / \mathrm{s} \text { the years in school drops. }\end{array}$ & $\begin{array}{l}\text { Carly moves her hand up and } \\
\text { down twice }\end{array}$ \\
\hline 79 & $\mathrm{R} 1$ & $\begin{array}{l}\text { So how would you describe the } \\
\text { relationship between these two indicators? }\end{array}$ & \\
\hline 80 & Amilia & $\begin{array}{l}\text { I guess really generally it's as you go } \\
\text { towards the equator the mean years in } \\
\text { school decreases and as you go away from } \\
\text { the equator the mean years increases. }\end{array}$ & \\
\hline 81 & $\mathrm{R} 1$ & And how strong do you think this is? & \\
\hline 82 & Amilia & 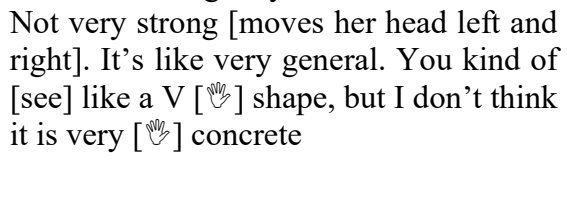 & $\begin{array}{l}\text { Stretches her hand and does } \mathrm{V} \\
\text { shape with her index finger. } \\
\text { Points with the whole palm } \\
\text { towards the (top/centre?) part of } \\
\text { the graph. }\end{array}$ \\
\hline 83 & $\mathrm{R} 1$ & $\begin{array}{l}\text { How are you referring to strength? How } \\
\text { do you see strength? }\end{array}$ & \\
\hline 84 & Carly & Like medium weak & Laughs \\
\hline 85 & Amilia & $\begin{array}{l}\text { Yah.. it's on the weaker [M] side. } \\
\text { Yah.. not very good. I mean it's [not] } \\
\text { something }\left[\mathbb{M}^{\mathbb{M}}\right] . \text { yah.. }\end{array}$ & $\begin{array}{l}\text { Moves her hand in two cycles to } \\
\text { the left }\end{array}$ \\
\hline 86 & $\mathrm{R} 2$ & $\begin{array}{l}\text { So what was it about the plot that makes } \\
\text { you say it's weak? }\end{array}$ & \\
\hline 87 & Amilia & $\begin{array}{l}\text { Ahm.. I don't know, I feels that there is } \\
\text { not... for me, when I am trying to see if } \\
\text { there is a trend, I put my hand [ } \mathrm{m} \text { ] on it } \\
\text { and see if I can see an actual line. } \\
\text { And in this case, I know it sounds stupid, } \\
\text { you can't really see an actual line, there } \\
\text { are too many outliers [ [ } 3 \text { ] from that } \\
\text { general trend, so I don't think it's concrete }\end{array}$ & $\begin{array}{l}\text { moves her left hand into } \\
\text { diagonal line and then moves her } \\
\text { right hand into a crossing diagonal } \\
\text { line and as if stressing this } \\
\text { shape/gesture }\end{array}$ \\
\hline
\end{tabular}


enough to say that. ...... I don't know if

that makes sense.

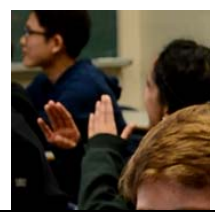

Summary of presentations and discussion in the initial phase Facility in covariational reasoning was not universally demonstrated among the three presenting groups; some described multivariate relationships using pairwise bivariate reasoning, and some ignored variables and relationships that were apparent in the data in a local or global view. Regarding describing relationships in terms of the characteristics of the trend, only one group described the shape, and that group described a non-linear trend as linear. Direction of the trend was explicitly mentioned or described only after prompting in the class forum. While two groups discussed the strength of the association and clusters in the data, they revealed only partial understanding. No group mentioned slope. Perception of scatter and outliers were portrayed by two groups, although their comments were incomplete. In the class discussion, when presented with a scatterplot showing a complex non-linear relationship, students' attempts to make meaning were supported by substantive usage of gestures to aid their verbal description of complex non-linear modeling of the trend and the scatter in the graph.

\subsection{FURTHER EMERGENCE OF IDEAS}

Further promotion of the emergence of ideas in students' reasoning about covariation in modeling terms took place in the "Recreating the scatterplot from the trend" exercise that followed the discussion about Big Data (part of activity 3a, described in section 3.2). In this exercise, a student was tasked with drawing a scatterplot based on the verbal description provided by his/her classmates who could not reveal the context. The particular scatterplot showed the winning times of the Olympic 100 meter race over time, for men and women. Examples from Ron are used to illustrate how the visual application of interpretive microanalysis allowed identification of students' main steps taken to model covariation and the characteristics of the trend, in particular, following the instructions of the class (Figures 5 through 16). While some of the visual storyline is self-explanatory, we highlight a few of the steps, followed by a compact summary of the exercise.

Analysis of both the visual and textual transcripts identified the following stages in the enactment of "Recreating the scatterplot from the trend" exercise:

1. Set the scene: drew axes, scale, and labels

2. Initialized plot with data points that followed a trend

3. Shifted from points to drawing a trend line capturing the basic shape and direction

- Corrected the line direction and verified shape

- Adjusted position (corrected the line i.e., y intercept starting point)

- Determined the degree of the slope

- Reflected the data context in the graph

- Captured clusters in the data (caused by the differing trends for men and women) through the addition of another trend line (with appropriate direction, slope, shape)

- Added scatter around the two trend lines (Ron added dots above and underneath the two lines) 


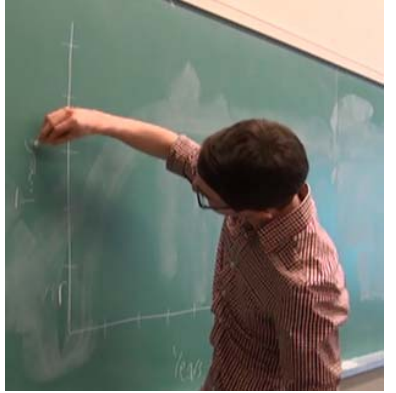

Figure 5. Drew axis, scales, and axis names

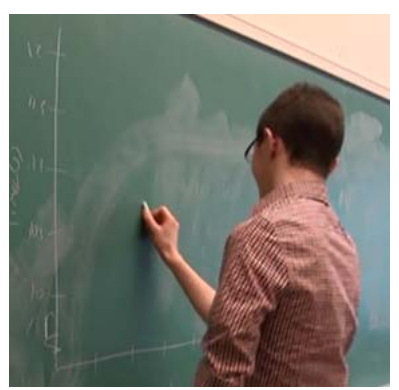

Figure 8. Drew free form line to follow a negative slope that started from 11 on the vertical axis

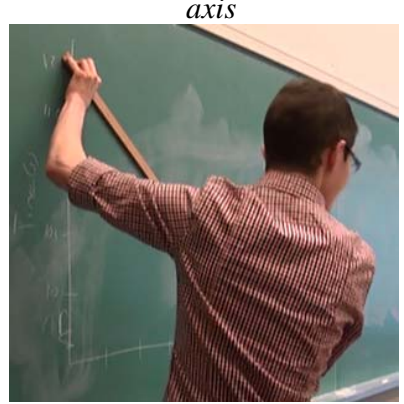

Figure 11. Raised the ruler and adjusted the slope until a student says "yah"

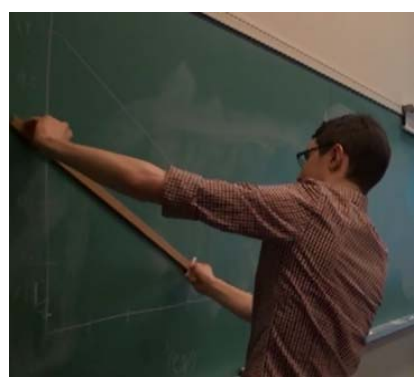

Figure 14. Ron dragged the ruler in parallel to the first line and the class instructed him how far apart to place the lines

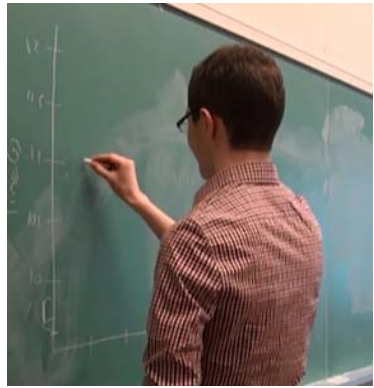

Figure 6. Started drawing cases in positive direction

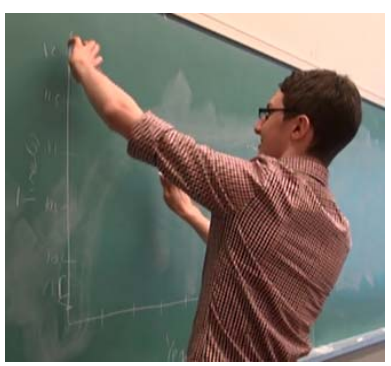

Figure 9. Got corrected to start the slope from 12 on the vertical axis

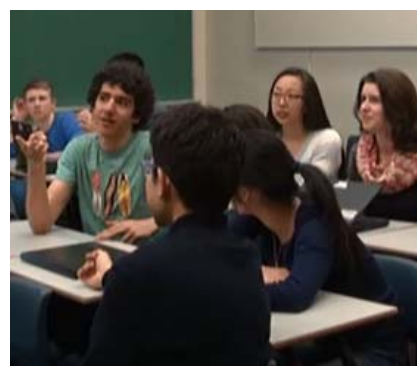

Figure 12. A discussion in class arose about the data regarding whether there were two groups

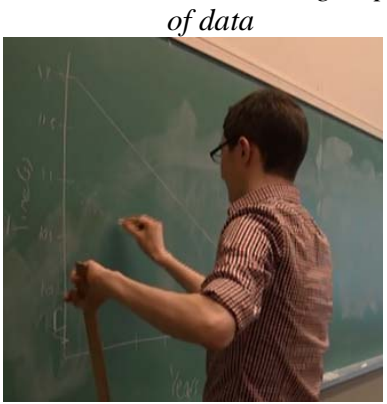

Figure 15. He added dots [scatter] around the lower line

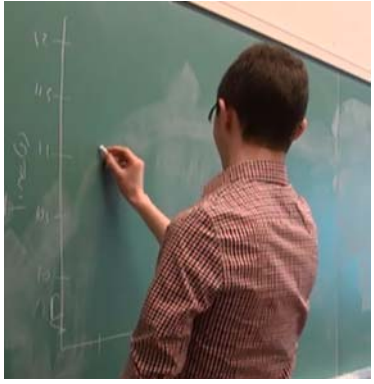

Figure 7. Started to draw points to follow a trend line with a positive slope when a student said clearly "negative slope with a lot of fluctuation"

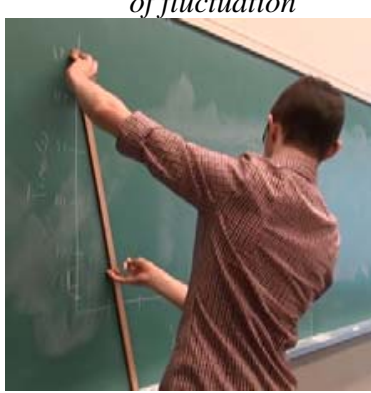

Figure 10. Consulted about the steepness of the slope: "to here?"

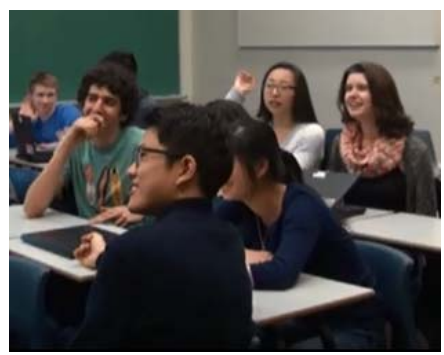

Figure 13. Sharon revealed the context - that the two groups are men and women

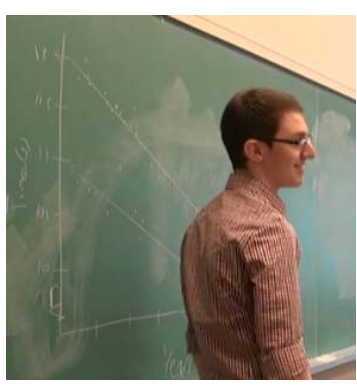

Figure 16. After finishing the scatter around the upper slope, Ron looked at the students, checking if it is correct 
We note that Ron's "default" for the direction and shape of the trend was positive and linear, without separate clusters. In contrast to the first activity, the students used vocabulary and concepts of modeling of covariation, including the direction, slope and position of the trend line, at an early stage of the exercise, without any intervention by the researchers-teachers. Students recognized that starting with a model and concepts of a model led to efficient communication of the nature of the data illustrated in the scatterplot. Relating to the context of the data helped reveal that the data were grouped in two clusters, which could be best captured through two trend lines - one for men and one for women. This took place after the initial structure of the data had been established. Finally, scatter was added around both trend lines, apparently in response to a need to create a more realistic graph rather than as a reflection of the strength of the association.

The exercise clearly promoted the emergence of ideas of the modeling of covariation and students recognized the value of modeling for communication about an association. However, due to the lack of sufficient discussion after the exercise, it is not clear whether a greater depth of understanding of the modeling concepts (such as the meaning of a slope and its connection to the association between the variables) was achieved by this activity.

\subsection{CONTINUATION AND CHANGE IN PERCEPTION OF MODELING FOR COVARIATION}

In this section, we examine the pitches three groups prepared for the newly elected mayor for suggested improvements (Activity 5). Each of these groups included at least one student from the groups whose Activity 1 presentations were analyzed in Section 3.1, although no student from Group 2 in Activity 1 was a member of the three groups whose Activity 5 presentations are analyzed here. While better comparisons would have been possible if the group composition remained the same for all activities, due to the dynamics of the class the groups changed. The pitches presented here are, in general, of average or higher quality than the pitches not presented. The three groups, their topics, and excerpts from the transcripts of their presentations are given in Table 6. It is important to mention that Activity 5 was more demanding on a technical level, while Activity 1 required applying only visual analysis of multivariate thinking. This will be further discussed in the limitations of the study.

Content analysis of the three group pitches is summarized in Table 7. Analysis of the nature of the covariational reasoning demonstrated in the presentations revealed that all three groups used bivariate reasoning. None of the three groups extended their reasoning beyond two variables in one graph despite opportunities in iNZight, for which there was previous instruction, to examine how the bivariate relationship differed for values of a third variable using either color-coding or plots of subsets of the data for each value of the third variable. This aspect was true for all 11 groups in both classes, with the exception of one group who examined how a bivariate relationship changed with different values of a third variable. Some students, including Galya, Tesa and Karin (Group B), did consider more than two variables but all graphs and analyses considered them pairwise. Some other groups in the class investigated questions such as the association between wealth and crime, with multiple variables available to measure crime.

All three groups related to the trend taking a global view of the scatterplot. Regarding the characteristics of the trend, all three groups discussed the shape with almost all using a straight line even when the relationship was curvilinear. An exception to this tendency for straight lines was Group B who fitted a curve to one of their graphs. Additionally,

Table 6. Students' statements from Activity 5, illustrating their modeling of covariation 
Group A Sharon, Amilia

(Sharon from Group 1 in Activity 1)

Research Question: Are home prices and major crime correlated?

So this is our graph that we have.. and it does seem to have a general trend, however.. there is a lot of scatter.. it's not the best relationship between them. (Sharon)

Group B Galya, Tessa and Karin (Galya from Group 1 of Activity 1) Research Question: Does the relative wealth of neighborhood affect crime? This will be based on:

House prices and total crime incidences House prices vs Robberies

Home prices vs vehicle theft

Total population vs total crime (as a control

Ok.. so overall... over our graphs we found there is a positive correlation in our control of Total Population versus Total Crime, but then overall we found negative correlation in.. if you compare the different types of Crimes compared to House Prices and I guess we usually, most of our trend lines were linear, but we found that the relationship was not that strong in this most of our things. (Karin)

Group C Annie, Nicole

(Annie from Group 3 of Activity 1)

Research Question: Is there a relationship between cervical cancer screening and home prices?

So we found that between home prices and cervical cancer screening there was a weak positive correlation, and the trend line was linear. (Annie)
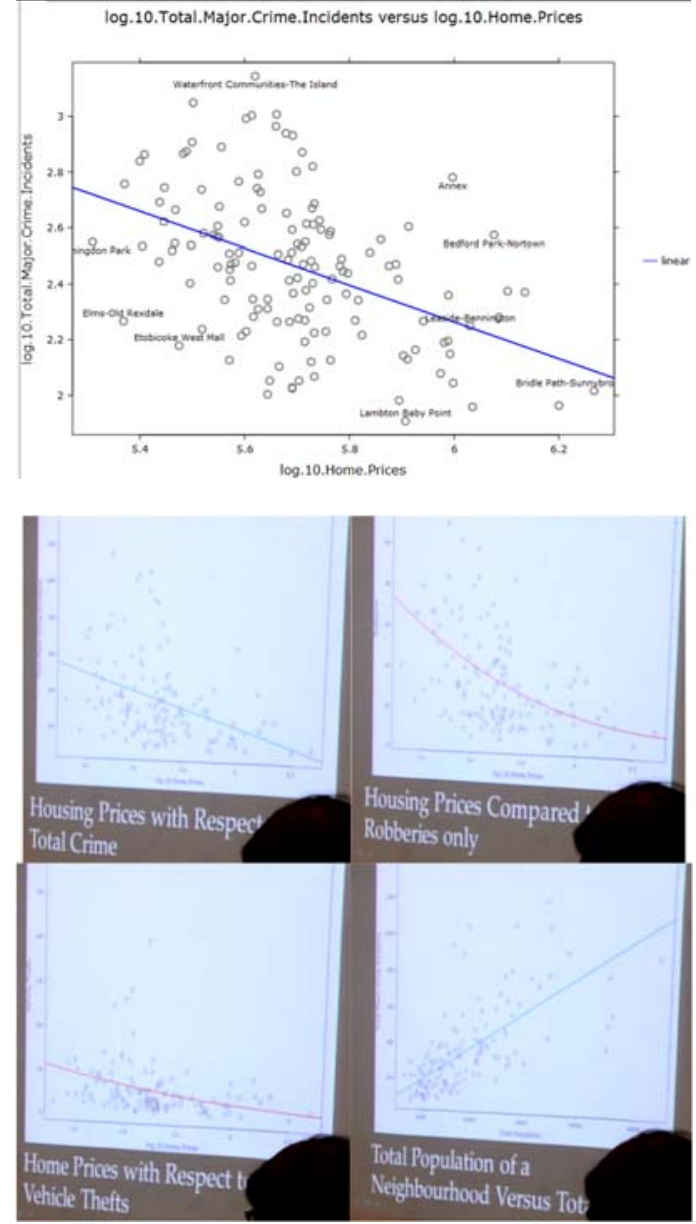

Cenvical.Cancer.Screenings versus Home.Prices

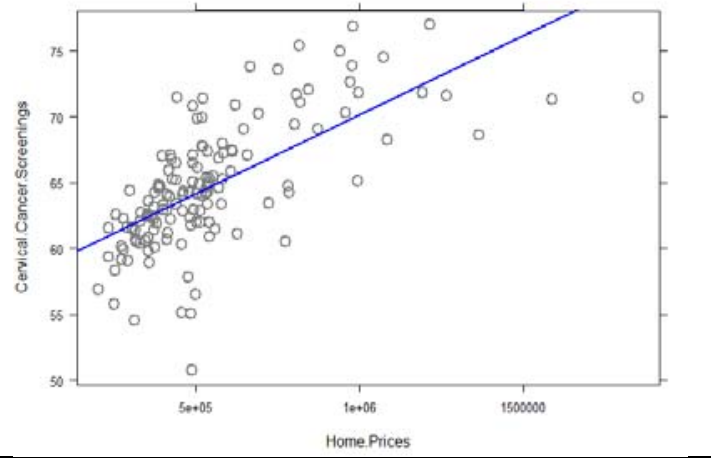

when asked by their teacher whether the straight line was appropriate for their data, Sharon (Group A) replied that they tried to fit a quadratic model. She added that they abandoned it in favor of a linear model because although the quadratic model captured the trend for most of their data, the relationship was monotonic decreasing and the 
Table 7. Students' use of covariation and modeling in presentations of Activity 5

\begin{tabular}{llll}
\hline Characteristics & Group A & Group B & Group C \\
& Sharon, Amilia & Galya, Tesa, Karin & Annie, Nicole \\
\hline Covariational reasoning & $2 \mathrm{x}$ & $2 \mathrm{x}$ & $2 \mathrm{x}$ \\
Trend & $\mathrm{x}(\mathrm{L}, \mathrm{E})$ & $\mathrm{x}(\mathrm{L})$ & $\mathrm{x}(\mathrm{L}, \mathrm{E})$ \\
Shape & $\mathrm{x}(\mathrm{L}, \mathrm{E})$ & $\mathrm{x}(\mathrm{L}, \mathrm{E})$ & $\mathrm{x}(\mathrm{L})$ \\
Slope & $\mathrm{x}(\mathrm{L})$ & & \\
Direction & $\mathrm{x}(\mathrm{L}, \mathrm{E})$ & $\mathrm{x}(\mathrm{L}, \mathrm{E})$ & $\mathrm{x}(\mathrm{L}, \mathrm{E})$ \\
Strength & $\mathrm{x}(\mathrm{L}, \mathrm{E})$ & $\mathrm{x}(\mathrm{L}, \mathrm{E})$ & $\mathrm{x}(\mathrm{L})$ \\
Clusters & {$[\mathrm{x}(\mathrm{L})]$} & & \\
Scatter & $\mathrm{x}(\mathrm{L}, \mathrm{E})$ & & {$[\mathrm{x}(\mathrm{L})]$} \\
Outlier & & $\mathrm{x}(\mathrm{L})]$ \\
\hline
\end{tabular}

Mentioned: $2 \mathrm{x} / 3 \mathrm{x}=\#$ of times; $\mathrm{x}(\mathrm{E})=$ explicitly; $\mathrm{x}(\mathrm{L})=$ literally $\mathrm{x}(\mathrm{L}, \mathrm{E})=$ explicitly\& literally; $[\mathrm{x}$ (L)] literally but not in the right meaning.

directional change of the quadratic function was not sensible in the context of the data. From the expert view, all three groups fit linear models in situations where curvilinear models would have provided a better fit to the data, as seen in other studies (Casey, 2015; Moritz, 2004). In situations where a linear model was appropriate, students ignored features of the data (outliers, uneven scatter) that indicated lack-of-fit of a linear model. While discussion of the slope was still almost absent from the description of the associations (apart from one L mention by Sharon, Group A), all three groups mentioned and explained correctly the direction of the trend. Of particular interest was Group A's (Sharon and Amilia) introduction to their study, in which they described their a priori hypothesis about the model: "our hypothesis was that they were... they are correlated except in a negative way, we assumed that there would be a negative slope in that... as

home prices go up, crime rate goes down and vice versa" (Amilia, 3). This is a clear description of a model, focused on its direction, that is based on describing what they understood about the nature of the variables rather than what they observed in the data. In this instance, they were thinking about a model as a description of a phenomenon, rather than a tool to give a cleaner picture of messy data. They went on to describe their investigation and how the data were consistent with the model they expected.

All three groups referred to strength of their models in a way, through phrases such as "it's not the best relationship between them" (Sharon), "does not really show much of a correlation, a very strong one at least" (Galya) or "a weak positive correlation" (Annie). Both Groups A and C connected their comments about strength to the amount of scatter, but with varying accuracy (Sharon more, and Nicole less). None of these groups summarized the strength of the relationship with the correlation coefficient, despite previous written instruction on how to calculate it in iNZight, and only one group from both classes calculated it.

Deviations in the data from the overall trend characterizing lack of fit, including separate clusters and outliers, were not mentioned in the student presentations. Only one group mentioned "outliers" literally but demonstrated an incorrect understanding of the term (Group C). Group A confused clusters with scatter. Group C expressed concern with the lack of fit of the model, but confused data points which did not fit a model because of its incorrect shape with outliers.

Comparing the summaries of the use of covariational reasoning and modeling of covariation in the students' initial (Table 4) and final (Table 7) presentations, all students used global bivariate reasoning at the end of the unit, not reverting to a local or almost 
univariate view of the data (as was seen in the Activity 1 presentation of Annie and Chad, Group 3). Despite their experience with multivariate visualization of relationships in Gapminder and instruction in coding and subsetting the data into groups by the values of a third variable in iNZight, students in both classes, except for one group, restricted their descriptions and modeling to two variables at a time.

Regarding students' use of characteristics of models for covariation, from the first to the fifth activity there was a demonstrated increase in the knowledge and perception of the characteristics of the trend, particularly the shape, direction, and strength. All groups could articulate the direction and its meaning, and relate to the strength of the association. Students' ability to recognize clusters and outliers and relate to their roles in specifying an appropriate model and how well it fit the data either did not progress or was less relevant in the various Wellbeing Toronto investigations or their representations in iNZight. However, students' discussion of scatter was more substantial in the final presentations than in the beginning activity of the unit.

\subsection{DESIGN PERSPECTIVE}

This section addresses the second research question, looking at students' emergent covariational reasoning and its modeling through the design features that were used to promote it. We present our evidence-based conjectures, from which we would like to highlight three main areas of emergent reasoning: 1. covariational reasoning in a multivariate setting, 2. seeing models of covariation beyond linear, and 3. modeling of covariation. For each of these areas, Table 8 gives a summary of the design features that might have been instrumental in promoting them.

The first type of emergent reasoning in Table 8, covariational reasoning in a multivariate setting, is an important concept in data science and in making sense of big data, reflected recently in the new GAISE document (Carver et al., 2016). Two main tools were used to promote it in this program: Gapminder and iNZight. Using Gapminder, with its built-in tools to examine how relationships change over time and with population and region of the world, two out of the three groups reasoned in a multivariate way already in the first activity. At the end of the unit, using a different tool (iNZight) for which it was necessary for students to proactively include additional variables, the students in both classes presented graphs and discussion demonstrating only bivariate reasoning, apart from one group. The Gapminder tool appeared to encourage

Table 8. Emergent covariational reasoning and related design features

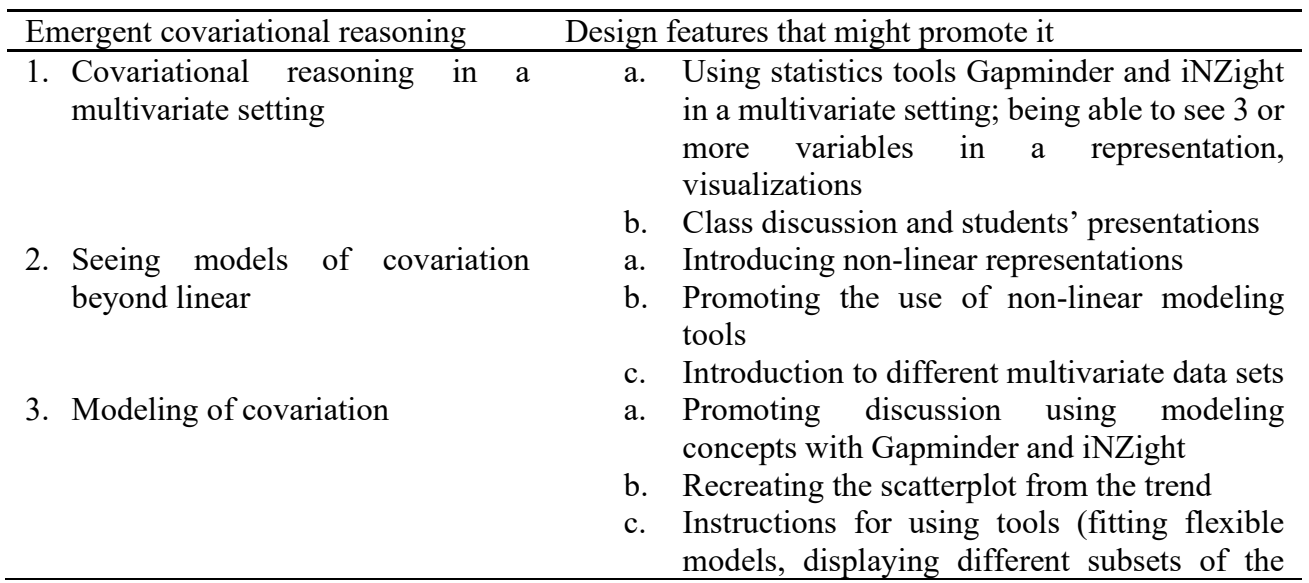




\begin{tabular}{ll}
\hline Emergent covariational reasoning & Design features that might promote it \\
\hline & $\begin{array}{l}\text { data based on a third variable, color-coding, } \\
\text { calculating the correlation coefficient) in } \\
\text { iNZight }\end{array}$ \\
\hline
\end{tabular}

multivariate reasoning through its use of automatic color-coding and its ability to animate over time at the touch of a button and some students considered how the bivariate relationship they were examining varied over time. But even though it was automatically provided, the role of color-coding by continent was not considered by most students until prompted. The modeling capabilities built into iNZight allow plots to be color-coded and / or subsetted into various graphs by the values of another variable. Few students used these features of iNZight, suggesting that more instruction might be needed for students to fully make use of them.

The unit was designed to promote the second type of emergent reasoning in Table 8, seeing models of covariation beyond linear. To this end, we used different multivariate datasets, some of which included non-linear relationships, and purposely introduced some data with a curvilinear trend (e.g., the relationship between how far to the north a country is and average years of schooling in Activity 1). The students struggled with expressing non-linear associations and used complex gestures to aid their descriptions. Despite this exposure to non-linear relationships, in the last activity we still saw the modeling of covariation to be biased towards straight line models.

Over the course of the unit, students increased their use of the third type of emergent reasoning in Table 8, modeling of covariation. This was promoted by discussions throughout the unit using modeling concepts, as mentioned previously. It was also promoted by recreating the scatterplot from the trend exercise and using modeling tools in iNZight. It is apparent that only some concepts were considered and some tools were used. Questions and suggestions arising from these three features will be further considered in the discussion as well as limitations of the findings based on the unit design.

\section{DISCUSSION}

We studied the characteristics of students' modeling of covariational reasoning in the context of big and multivariate data, how it changed during the three-week program, and what design features might contribute to their covariational reasoning. Findings about 12th grade students' modeling of covariation in the context of big data show that the students progressed describing covariational reasoning in modeling terms, attending in particular to direction, shape, and strength. In terms of shape, even after learning and experimenting with fitting non-linear curves, many students demonstrated a tendency to fit a linear model even at times when the relationship was curvilinear. Our observations reinforce findings from previous studies (Casey, 2015; Moritz, 2004).

In the final activity of the unit, the three presenting groups represented and described the relationships in bivariate terms, with more homogeneity in level of vocabulary and sophistication in presentation throughout the class. Although students were encouraged to use multivariate tools and were given tools designed to allow multivariate reasoning (Gapminder in the $1^{\text {st }}$ activity and iNZight in the last), students in the final activity presented arguments based on bivariate relationships, even when making a pitch about associations involving multiple variables. They didn't yet utilize the knowledge and skill they learned of representing association between three variables in one graph, possibly owing to the lack of proficiency with the tool. We believe that developing student confidence in multivariate reasoning will require careful scaffolding to allow them to acquire fluency with, for example, making conclusions about a relationship between two 
variables after the data have been separated into subsets by the values of a third variable. Additionally, the availability of time as a third dynamic variable in Gapminder seemed to lend itself more easily to multivariate reasoning, as observing how a relationship evolves over time is perhaps a natural introduction of a third variable. Similarly, students' tendency to use linear models in situations where curves would provide a better fit to the data demonstrates the need for greater guided support in their development of a more flexible approach to modeling.

In this study, our approach to modeling focused on generative/descriptive models (e.g. Shmueli, 2010), starting with the data and not with the models themselves (Lehrer \& Schauble, 2004). We used the sense of models as "conceptual systems, [..] that are used to construct, describe, or explain the behaviors of other systems" (Lesh \& Doerr, 2003, p. 10). As part of the theoretical contribution of our study, a suggested concept map (Figure 1) offers components of models for covariation. Some of these components, such as characteristics of the trend, emerged in the students' reasoning and provided students with concepts that could be applied to the task at hand and be used to describe and explain the behavior of other systems in the world. For example, the direction of a trend or the shape of a model for an association can describe or explain the relation between literacy and fertility rate in countries of the world, or wealth and crime rates in neighborhoods of a city. In both cases, an appropriate model can be fit to represent the relationship. The strength of an association is not only a value or theoretical description, but it is also of value in creating arguments to influence a mayor's decisions. In the recreating the scatterplot exercise, students quickly discovered the efficiency of describing the data in terms of a model. Thus, there is evidence of connection between modeling terms, the phenomena they describe, the "modeling agency" (i.e., the students' mental representation), and the statistical tool. Students appear capable of connecting conceptual modeling terms (abstractions) to phenomena (the natural, concrete world) to create meaning. Furthermore, we see emerging a reciprocal relationship between covariational reasoning and the modeling of it. Covariation can be more economically described by using modeling language to characterize the different aspects of the relation. In addition, using modeling language promotes covariational reasoning itself by capturing the nature of the association in global covariational terms. An example of this can be seen by contrasting Annie's presentations in the first and fifth activities. She moved from observing local patterns of change, looking at the change over time of one variable (fertility) in one country (the US), to a more sophisticated and detailed analysis of the correlation between house prices and cervical cancer screening. Though her group did not use a model with the most appropriate shape, her attempt at covariational reasoning in modeling terms represents epistemologically capturing both covariation and modeling.

Representational gestures were found to be another embodiment of expressing statistical reasoning and demonstrating covariational reasoning and the modeling of it. A strong association, described as "when I can put my hand on it," adds another overlay of understanding to our interpretation of students' reasoning and brings to life, through gestures and verbal expression, a conceptual system.

Evolving ideas from this study contribute to the discussion of different aspects of modeling of covariation at the secondary school level, including how technology tools that provide opportunities for multivariate reasoning and flexible modeling can support and utilize emerging understanding in these areas, how we might integrate big data in addition to smaller data, and how we might develop statistical thinking through the use of current datasets involving measurements relevant to global and regional issues. Starting from our findings, several additional questions can be proposed regarding concepts students use when modeling covariation; for example, how to promote a more flexible approach to 
modeling (particularly shape) and how to encourage the development of facility in multivariate reasoning, perhaps by developing facility in asking critical context questions that promote the need for multivariate reasoning and how to encourage evaluation of a model as part of the modeling process.

Additionally, our study suggests an exploratory design sequence for developing covariational reasoning at the school level within the complex context of big and open data, through the use of interactive technology and activities that prompt the students to support policy arguments with sound statistical reasoning. It also points to the scaffolds needed with statistical tools to promote modeling of covariational reasoning.

Our findings are limited to our modest attempt in the settings described. Limitations also arise from the difference in the demands of activities 1 and 5 that might be in some sense not comparable, since using iNZight is more technical and involves modeling tools. This technicality might have impacted students' ability to represent and therefore articulate multivariate reasoning in response to their research questions. We suggest that further development of the unit to a longer curriculum with additional conceptual and technical scaffolds would yield a greater impact on students' covariational reasoning and modeling of covariation in a multivariate environment.

\section{ACKNOWLEDGEMENTS}

We greatly thank the participating teacher, students and school who collaborated with us on this project. The study was supported through two postdoctoral fellowships for the first author by the Fields Institute for Research in Mathematical Sciences and the Department of Statistical Sciences at the University of Toronto.

\section{REFERENCES}

Agrawal, D., Bernstein, P., Bertino, E., Davidson, S., Dayal, U., Franklin, M., \& Widom, J. (2012). Challenges and opportunities with big data. A community white paper developed by leading researches across the United States.

Alibali, M. W., \& Nathan, M. J. (2012). Embodiment in mathematics teaching and learning: Evidence from learners' and teachers' gestures. Journal of the Learning Sciences, 21(2), 247-286.

Bakker, A., \& Gravemeijer, K. P. (2004). Learning to reason about distribution. In D. BenZvi \& J. Garfield (Eds.), The challenge of developing statistical literacy, reasoning and thinking (pp. 147-168). Dordrecht, The Netherlands: Kluwer Academic Publishing.

Barab, S. A., \& Squire, K. D. (2004). Design-based research: Putting our stake in the ground. The Journal of the Learning Sciences, 13(1), 1-14.

Batanero, C., Estepa, A., Godino, J. D. (1997). Evolution of students' understanding of statistical association in a computer-based teaching environment. In J. B. Garfield \& G. Burrill (Eds.), Research on the role of technology in teaching and learning statistics: Proceedings of the 1996 IASE Round Table Conference (pp. 191-205). Voorburg, The Netherlands: International Statistical Institute.

Ben-Zvi, D., \& Arcavi, A. (2001). Junior high school students' construction of global views of data and data representations. Educational studies in mathematics, 45(1-3), 35-65.

Beyer, M. A., \& Laney, D. (2012). The importance of "big data": A definition (Report No. G00235055). Retrieved from Gartner, https://www.gartner.com/doc/2057415/importance-big-data-definition 
Brown, A. L. (1992). Design experiments: Theoretical and methodological challenges in creating complex interventions in classroom settings. The Journal of the Learning Sciences, 2(2), 141-178.

Carver, R., Everson, M., Gabrosek, J., Rowell, G. H., Horton, N., Lock, R., Mocko, M., Rossman, A., Velleman, P., Witmer, J., \& Wood, B. (2016). Guidelines for Assessment and Instruction in Statistics Education (GAISE) College Report 2016. Alexandria, VA: American Statistical Association. Retrieved from http://www.amstat.org/asa/files/pdfs/GAISE/GaiseCollege Full.pdf

Casey, S. A. (2015). Examining student conceptions of covariation: A focus on the line of best fit. Journal of Statistics Education, 23(1). Retrieved from http://ww2.amstat.org/publications/jse/v23n1/casey.pdf

Chi, M. T. H. (1997). Quantifying qualitative analyses of verbal data: A practical guide. Journal of the Learning Sciences, 6(3), 271-315.

Cobb, P., Confrey, J., diSessa, A., Lehrer, R., Schauble, L. (2003). Design experiments in educational research. Educational Researcher, 32(1), 9-13.

Cobb, P., McClain, K., \& Gravemeijer, K. (2003). Learning about statistical covariation. Cognition and Instruction, 21(1), 1-78.

Engel, J., Sedlmeier, P., \& Woern, C. (2008). Modeling scatterplot data and the signalnoise metaphor: Towards statistical literacy for pre-service teachers. In C. Batanero, G. Burrill, C. Reading \& A. Rossman (Eds.), Joint ICMI/IASE Study: Teaching Statistics in School Mathematics. Challenges for Teaching and Teacher Education. Proceedings of the ICMI Study 18 and 2008 IASE Round Table Conference. Retrieved from http://iase-web.org/documents/papers/rt2008/T4P8 Engel.pdf

Fan, J., Han, F., \& Liu, H. (2014). Challenges of big data analysis. National Science Review, 1(2), 293-314.

Forbes, S., Chapman, J., Harraway, J., Stirling, D., \& Wild, C. (2014). Use of data visualisation in the teaching of statistics: A New Zealand perspective. Statistics Education Research Journal,13(2), 187-201. Retrieved from http://iase-web.org/documents/SERJ/SERJ13(2) Forbes.pdf

Franke, B., Plante, J.-F., Roscher, R., Lee, A., Smyth, C., Hatefi, A., Chen, F., Gil, E., Schwing, A., Selvitella, A., Hoffman, M. M., Grosse, R., Hendricks, D., \& Reid, N. (2016). Statistical inference, learning and models in big data. International Statistical Review 84(3) 371-389. doi: 10.1111/insr.12176.

Garfield, J., \& Ben-Zvi, D. (2008). Developing students' statistical reasoning: Connecting research and teaching practice. Dordrecht, The Netherlands: Springer.

Gil, E. (2014). Long term impact of promoting informal inferential statistical reasoning in an inquiry-based and technology-rich learning environment. (Unpublished doctoral dissertation, University of Haifa, Haifa, 2014.)

Gil, E., \& Ben-Zvi, D. (2011). Explanations and context in the emergence of students' informal inferential reasoning. Mathematical Thinking and Learning, 13(1-2), 87-108.

Gil, E. \& Gibbs, A. L. (2015). Big data in Math for Data Management - activities and teachers' guide. The Fields Institute for Research in Mathematical Sciences and The University of Toronto. [draft]

Gil, E. \& Gibbs, A. L. (2016, July). Introducing secondary school students to big data and its social impact: A study within an innovative learning environment. In Engel, J. (Ed.) Promoting understanding of statistics about society. Proceedings of the Roundtable Conference of the International Association for Statistics Education (IASE), July 2016, Berlin, Germany. Retrieved from http://iase-web.org/documents/papers/rt2016/Gil.pdf 
Gil, E., \& Slotta, J. D. (2015, June). Knowledge community and inquiry about big data among high school students with Interactive Orchestrated Learning Space. Proceedings of the Eleventh International Conference on Computer Supported Collaborative Learning (CSCL, June 2015). Gothenburg, Sweden: The International Society of the Learning Sciences.

Gould, R. (2010). Statistics and the modern student. International Statistical Review, 78(2), 297-315.

Gravemeijer, K. P. E. (2000). A rationale for an instructional sequence for analysing oneand two-dimensional data sets. Paper presented at the annual meeting of the American Educational Research Association, Montreal, Canada.

Kuhn Berland, L., \& Reiser, B. J. (2009). Making sense of argumentation and explanation. Science Education, 93(1), 26-55.

Le, D.-T. (2013), Bringing data to life in an introductory statistics course with Gapminder. Teaching Statistics, 35(3), 114-122. doi: 10.1111/test.12015.

Lehrer, R., \& Romberg, T. (1996). Exploring children's data modeling. Cognition and Instruction, 14(1), 69-108.

Lehrer, R., \& Schauble, L. (2004). Modeling natural variation through distribution. American Educational Research Journal, 41(3), 635-679.

Lehrer, R., \& Schauble, L. (2010). What kind of explanation is a model? In M.K. Stein, L. Kucan (Eds.), Instructional explanations in the disciplines (pp. 9-22). New York, NY: Springer.

Lesh, R., \& Doerr, H. M. (2003). Foundations of a models and modeling perspective on mathematics teaching, learning, and problem solving. In R. Lesh and H. M. Doerr, Beyond constructivism: Models and modeling perspectives on mathematics problem solving, learning, and teaching (pp. 3-33). Mahwah, NJ: Lawrence Erlbaum Associates.

McNeill, D. (1992). Hand and mind: What gestures reveal about thought. Chicago: University of Chicago Press.

Meira, L. (1998). Making sense of instructional devices: The emergence of transparency in mathematical activity. Journal for Research in Mathematics Education, 29(2), 121142.

Meskill, C., Mossop, J., DiAngelo, S., \& Pasquale, R. K. (2002). Expert and novice teachers talking technology: Precepts, concepts, and misconcepts. Language Learning \& Technology, 6(3), 46-57.

Moore, D.S. (1999). Discussion: What Shall We Teach Beginners? International Statistical Review, 67(3), 250-252.

Moritz, J. (2004). Reasoning about covariation. In D. Ben-Zvi and J. Garfield (Eds.). The challenge of developing statistical literacy, reasoning and thinking (pp. 227-255). Dordrecht, The Netherlands: Kluwer Academic Publishers.

Nagel, E. (1979). The structure of science: Problems in the logic of scientific explanation. Indianapolis, IN: Hackett Publishing.

Ontario Ministry of Education (2005). The Ontario Curriculum, Grades 9 and 10: Mathematics.

Retrieved

from http://www.edu.gov.on.ca/eng/curriculum/secondary/math910curr.pdf

Ontario Ministry of Education (2007). The Ontario Curriculum, Grades 11 and 12: Mathematics. Retrieved from .http://www.edu.gov.on.ca/eng/curriculum/secondary/math1112currb.pdf

Patton, H. J. (2002). Qualitative research and evaluation methods. Thousand Oaks: Sage Publication. 
Philip, T. M., Schuler-Brown, S., \& Way, W. (2013). A framework for learning about big data with mobile technologies for democratic participation: Possibilities, limitations, and unanticipated obstacles. Technology, Knowledge and Learning, 18(3), 103-120.

Prediger, S., Gravemeijer, K., \& Confrey, J. (2015). Design research with a focus on learning processes: An overview on achievements and challenges. ZDM, 47(6), 877891.

Reiner, M., \& Gilbert, J. K. (2004). The symbiotic roles of empirical experimentation and thought experimentation in the learning of physics. International Journal of Science Education, 26(15), 1819-1834.

Ridgway, J. (2015). Implications of the data revolution for statistics education. International Statistical Review, 84(3), 528-549. doi:10.1111/insr.12110.

Rubin, A., \& Hammerman, J. K. (2006). Understanding data through new software representations. In G. Burrill \& P. C. Elliott (Eds.), Thinking and reasoning with data and chance: 68th NCTM Yearbook (pp. 241-256). Reston, VA.: National Council of Teachers of Mathematics.

Sfard, A. (2007). When the rules of discourse change, but nobody tells you: Making sense of mathematics learning from a commognitive standpoint. The Journal of the Learning Sciences, 16(4), 565-613.

Shmueli, G. (2010). To explain or to predict? Statistical Science, 25(3), 289-310 doi: 10.1214/10-STS330.

Stephens, A. L., \& Clement, J. J. (2010). Documenting the use of expert scientific reasoning processes by high school physics students. Physical Review Special TopicsPhysics Education Research, 6(2). Retrieved from http://journals.aps.org/prper/abstract/10.1103/PhysRevSTPER.6.020122 . doi: 10.1103/PhysRevSTPER.6.020122.

The $\mu$ Group. (2001). Theory, video and mathematical understanding: An examination of what different theoretical perspectives can offer. In R. Speiser, C. A. Maher, \& C. N. Walter (Eds.), Proceedings of the twenty-third annual meeting of the North American Chapter of the International Group for the Psychology of Mathematics Education (Snowbird, Utah, October 18-21, 2001) (Vol. 1, pp. 343-379)). Columbus, OH: ERIC Clearinghouse for Science, Mathematics, and Environmental Education.

Thirunarayan, K., \& Sheth, A. (2013, November). Semantics-empowered approaches to big data processing for physical-cyber-social applications. In Proceedings of the Association for the Advancement of Artificial Intelligence 2013 Fall Symposium Semantics for Big Data. Arlington, Virginia. Retrieved from http://www.aaai.org/ocs/index.php/FSS/FSS13/paper/view/7567/7556

University of Auckland, Department of Statistics. (2014-2017). iNZight. Retrieved from https://www.stat.auckland.ac.nz/ wild/iNZight/index.php

Watkins, A. E., Scheaffer, R. L., \& Cobb, G. W. (2004). Statistics in action: Understanding a world of data. Emeryville, CA: Key Curriculum Press.

Wild, C. J. \& Meek, T. (2014). From data to insight (MOOC). FutureLearn. Retrieved from https://www.futurelearn.com/courses/data-to-insight/

Wild, C. J., \& Pfannkuch, M. (1999). Statistical thinking in empirical enquiry. International Statistical Review, 67(3), 223-265.

Wild, C. J., \& Seber, G. A. (2000). Chance encounters: A first course in data analysis and inference. New York: John Wiley \& Sons Inc.

Zieffler, A., \& Garfield, J. (2009). Modeling the growth of students' covariational reasoning during an introductory statistics course. Statistics Education Research Journal, 8(1), 7-31. Retrieved from http://iase-web.org/documents/SERJ/SERJ8(1) Zieffler Garfield.pdf 
EINAT GIL 15 Shoshana Persitz St. Tel-Aviv 69378 Israel 